\title{
Elements influencing the success of Human Resource Information System
}

\author{
Dinusha Dissanayake ${ }^{1 *}$, Nandasena ${ }^{2}$ \\ Graduate, University of Peradeniya, Sri Lanka ${ }^{1}$ \\ Senior Lecturer, University of Peradeniya, Sri Lanka² \\ dinusha.d.dissanayake026@gmail.com ${ }^{1 *}$, clap77772003@yahoo.co.uk ${ }^{2}$
}

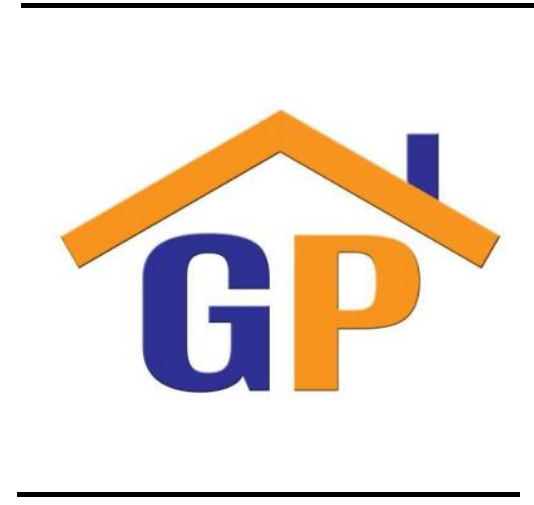

Article History

Received on 14 January 2020

$1^{\text {st }}$ Revision on 22 January 2020

$2^{\text {nd }}$ Revision on 10 February 2020

$3^{\text {rd }}$ Revision on 4 June 2020

$4^{\text {th }}$ Revision on 29 August 2020

$5^{\text {th }}$ Revision on 3 November 2020

Accepted on 4 November 2020

\begin{abstract}
Purpose: Due to the upgrade of technology, it has swapped the methods of controlling human beings in companies. In this context, finding the elements influencing the success of the HRIS in ABC manufacturing (Pvt) Ltd was the current research motive.
\end{abstract}

Research methodology: The study design was deductive and quantitative. Moreover, primary data with Scale questionnaire was utilized for data gathering. 30 executives were selected in ABC manufacturing (Pvt) Ltd have directly dealt with the HRI System. Further, data analysis did through regression analysis.

Results: The results confirmed that the success of HRIS was significantly impacted by the internal environmental elements and the external environmental elements. Also, found that internal environmental factors have the highest influence on the success of HRIS compared with the rest.

Limitations: The respondents chosen for the study were 30 in one single company. Instead, the researcher selected two determinants only.

Contribution: The researcher is motivated through this study because electronic, personal applications are now highly concern in local companies. The research findings can apply to organizations in third-world profiles to boost their HRI systems' efficacy.

Keywords: Human Resource Information System (HRIS), Internal environmental elements, External environmental elements

How to cite: Dissanayake, D., Nandasena, N. (2019). Elements influencing the success of Human Resource Information System. Annals of Management and Organization Research, 1(1), 65-75.

\section{Introduction}

The technology-driven global business contexts increased the competitiveness among firms now a day. Moreover, most organizations adopt the technology for their organizational operations, intending to raise efficacy. When referring to human capital functions, most companies adopted technology to manage human resources effectively. Moreover, this will save time, effort, and the organization's cost, finally enhance overall organizational effectiveness.

As a result of the upgraded technology, it has modified the pattern of controlling persons in companies. Now they treated people as their core asset, which generates the best return for their companies. Computer intelligence provides a platform to convert traditional firm policies to modern electronic, human resource policies. HRIS is the foremost substitute for electronic, personal control, which recognizes the value of managing human capital and increasing overall organizational effectiveness.

Human capital considers a powerful asset and a tool that can achieve corporate vision and mission. Compared to other assets, human capital is the most challenging asset to coordinate and control. However, the nature of human capital is difficult to manage concerning physical assets. The idea of electronic, human capital intelligence (E-HR) refers to the adaptation of computer retrieval to human 
capital operations through digital platforms employ with the infobahn and computers (Kagehi S. j., 2015). Blending the technology with personal control increases human capital management effectiveness in the firm, leading to minimizing the errors and misconduct in the main operations. Most of the companies today use technology to manage people. The HRIS won the challenge of working with big data, encouraging both managers' and workers' motivation.

Technology becomes the blood of organizations today. Human interactions with computers generated the best output in the office environment. In this context, it is crucial to find the elements influencing the success of the HRIS in manufacturing companies. Instead, the involvement of technology in the production-oriented process generates quality output to the customers (Anitha \& Aruna, 2015). In manufacturing organizations, they use more labor for their operations. So there is an enormous HR role to play in managing people. An effective workforce leads to generate a high return and profits for the firm. Several elements must be considered before adopting HRIS, which operates internally (factors inside) and externally (outside) factors. Organizations can use an intelligence system for HR functions, mainly in the payroll.

This study further highlights the difficulty of control of human assets without the use of technology. The new theories formulated for electronic HR, which explains the significance of adaptation technology for HR operations. Besides, those theories align the corporate strategies to HR strategies using technology. The empirical studies demonstrated the significance of technological adaptation in the firm's operations. HRIS help modern firms to manage their people effectively. However, there is a lack of studies on elements influencing the success of HRIS in the local context.

HRIS help to satisfy the requirements of stakeholders effectively compared with traditional manual operations. HRIS can adopt ground level to top-level for processing meaningful information. Through the HRIS, organizations can convert complex transactions to simplex levels. HRIS database is the finest tool for tracking human-related data in business firms. According to (Badhurudheen, 2018), cloud HRIS is the new trend these days. Moreover, cloud systems minimize physical storages and enhance the high security of the information. The cloud systems guaranteed privacy.

Networking often facilitates the HRIS to go beyond the local areas that the internet helps expand the range of HRIS all over the world. Through this platform, managers can track their employee data anyplace in the universe within a few minutes. Internet bought novelty to the firms. The concept of Global village has increased the value of the management information systems more today. The main advantages of HRIS are easy information access, cost advantage, enhance efficiency, and access to better service. Moreover, improved data quality, systematic processing, speed, and provide trusted results. Because of all these pros finally increase organizational productivity (Anitha \& Aruna, 2015).

Environmental changes positively influence labor demand and supply equilibrium, provided by the organization's market-determined internal HR policies. Through the HRIS, organizations can record market-sensitive data quickly and effectively. Moreover, HRIS consisted of the programs of employee profiling, compensation, budgeting, communications, performance evaluations, etc.

According to (Noutsa, Wamba, \& Kamdjoug, 2016), HRIS provides proper data storage, effective tracking, quick updating, and formulate systematic data for lower-level to top-level decision making. Further, pointed out that HRIS enhanced the total quality management, customer loyalty, plus innovation.

Human resource management's development captured the information technology to transform the traditional human-related functions to digital HR functions. HR professionals were reengineering their formal process to online. High performing computers help keep the acceleration and the caliber of HR information (Wijethilaka, 2016). However, information technology improves the overall efficacy and creamy of the institution by reducing paper works. At the same time, HRIS help to achieve the green concept in the firm. The digital operations were more accurate and complied with less wastage when comparing to manual processes.

Most of the white-collar companies rely more on HRIS to strengthen the efficacy of the human resource department. Furthermore, HRIS smooth the administration function as well. In crises, HRIS plays a significant role in generating strategic information for strategic decisions (Taylor \& Francis, 2017). Further, HRIS tools strengthen the internal control integral of the business. There was a 
massive competition between vendor companies for HRIS. This competition creates high-quality HRISs for the customers.

Moreover, HRIS enhance worker productivity and reduce the replacement costs of employees. Mainly, HRIS generates the best rate of return by lowering unwanted expenses incurred in the firms. Electronic engagements to the business process often increase the efficiency and effectiveness lead to achieving a competitive advantage.

The whole world realizes that artificial intelligence is a critical investment in a business that catches a competitive advantage. Corporate entities across the globe recognize the value of employees as an intellectual resource. The majority of the CEOs in the companies mentioned that human capital is the most precious asset in a business (Wijethilaka, 2016). Hence, the whole world realizes that computer interaction into a business catches market leadership. In an organizational context quality, people yield the best return on investment to the company. Managing people are critical challenges in a dynamic corporate environment. HRM plays an indispensable part in managing human capital properly to attain corporate dreams. Technology adaptation becomes famous in the contemporary business environment integrated with the functions of accounting, finance, marketing, personal management, administration, and production. Technological involvement increases the smooth operations and the efficacy of the corporate process. Simultaneously it will enhance the overall organizational efficiency by reducing the unwanted time, wastage, duplications, loess, etc.

In the dynamic business environment, firms are responsible for introducing innovations that reason to absorb continual cut-throat advantage. Organizations' can gain market leadership through the adaptation of new technology to the current operations. It is challenging to manage a larger workforce in manufacturing organizations using manual methods. Furthermore, artificial intelligence is the best tool to minimize business complexity. HRIS was often used to transform manual human-related functions to electronic, human-related functions.

HRIS invokes the integrated electronic processing of human-related activities in business firms. The prominent portrayal of the HRIS is to generate meaningful HR related data for organizational decision making. However, firms need the support of experts to adopt technology to HR functions. Organizations can develop their HRIS system in-house or outsourced. To retain efficiency and effectiveness, the HRIS must best fit the HR context in the firm.

Moreover, human resource managers have a crucial part to play in the adaptation process of HRIS. The rivalry between firms arises because of the competency of people. Blue-chip business firms realized that quality human capital generates a competitive advantage to the business. Market winners always produced innovations using their competent workforce (Genc, 2014). Without a skilled workforce, a competitive advantage becomes a dream. Moreover, companies unable to attain their strategic directions on time. In this scenario, HRIS helps to align HR strategies to prolonged goals.

The top performers in the corporate sector realized that employees' competency was more significant than their physical assets. Therefore, it recognized humans as a requisite part of the corporate culture. From the 1890 s to the modern era, human capital management evolution was systematically developed as a welfare function, labor management, personal management, human-related management, human capital, and a human capital business partner. It clearly shows how the industry recognized the value of the people. There was a side of finance and strategic importance in modern human-related management universally. In today's business context, HR is a value-added operation comparing to the past.

In the past, top managers did not realize the dominance of technology adaptation to business functions. At that time, human resources became just HR administration and maintenance. Instead, traditional HR practices are now moving to digital HR practices. Modern human capital management creates value for the firm instead of involving strategic decision-making by creating business value through people's strategic direction. Resources categorized as Money, Men, Materials, Machinery, and methods in accounting. These resources also are classified as physical resources and human resources. Men are the most identical and significant asset compare to others (Anitha \& Aruna, 2015). The beauty here is physical resources activate through human resources. Therefore, the proficient workforce utilizes other resources successfully to attain the goals in the organization. Human resource leadership engages in strategic decision making across the business. However, technological 
applications increase the firm's efficiency plus workers' performance. The empirical findings confirmed that the adaptation of the HRIS motivates the office Staff. Moreover, environmental factors closely integrate with HR functions. Managing people is a critical and most challenging function in today's business context.

Competent workforces are the pivotal input to the production process. Human beings play a significant role in considering the achievements of a company. It is challenging to track information and convert that information to meaningful data because of people's uniqueness. Because of this reason, humanrelated activities become complicated in the manual operation environment. Researchers and professionals have realized that technology adaptation was the best solution to minimize this workplace complexity over the past few decades. Traditionally, personal related activities were recognized as an administration function other than the strategic position.

Moreover, human resource management identifies as a supporting activity than a primary activity. At that time, managers and owners did not see any direct collision of HR in the decision-making process due to tremendous concern about the production processes. Traditional personal management functions are concerned about monitoring and governing the employees. Specially focused on administration and maintenance activities, but did not engage with the corporate planning and strategic decisions. Furthermore, when it comes to the modern business context, now human capital management becomes a strategic activity through the HRIS. HRIS provides valuable information for industrial decision making.

To acquire a competitive advantage majority of organizations adopt HRIS. Sometimes, organizations resist technology adaptation due to the cost, including HRIS. Purchasing customized HRIS is a suitable answer to this issue. Moreover, the software and hardware cost, maintenance issues, and privacy were significant to HRIS implementation (Genc, 2014). In line with the interpretation of (Taylor \& Francis, 2017), significant obstacles in adopting HRIS were insufficient funds, lack of knowledge, and less support of managers. Furthermore, training and development is a primary need for the successful adaptation of HRIS (Bullmash, 2015). Because of the above obstacles, HRIS adaptation was a problem in small scale firms.

Identify the elements influencing the success of the HRIS in ABC manufacturing (Pvt) Ltd was the main objective. Instead, what elements affect the success of the HRIS in ABC manufacturing (Pvt) Ltd was the study's research problem? The researcher motivates through this study because it is in the local context. Implementations of electronics, human-related practices are now becoming popular in local ground companies. The researcher explores the most prominent elements that influence the HRIS system's effectiveness in this research's local context. Age, education, performance, and social factors had a constructive influence on HRIS adaptation (Noutsa, Wamba, \& Kamdjoug, 2016). Furthermore, the significant elements of the HRIS lead to achieving the organization's critical goals successfully. Finally, effective HRIS meets the whole success of the business.

\section{Literature review and hypotheses development}

The web and artificial intelligence become the central part of modern corporations now a day. Organizations are trying to adopt electronic practices to their operations is now a day to improve the overall organizational performances and effectiveness. In this scenario, information systems become a significant part of the decision-generating process. Moreover, when considering human capital management, HRIS plays a vital role. According to (Anitha \& Aruna, 2015), HRIS is the bridge to merge HR and IT.

Further, HRIS firms can make their decisions effectively and generate meaningful information when necessary. Moreover, the HRIS creates a platform for decision-makers to find the information for their decisions. The research scholar of (Anitha \& Aruna, 2015) mentioned that from the 1960s onwards, organizations used electronic practices for personal management concerning the functions of planning, administration, coordination, and control. The previous research of (Kagehi S. j., 2015) found that organizational characteristics, IT planning, corporate culture highly influence the execution of HRIS in the IT firms in Kenya. In line with the review conducted by (Wijethilaka, 2016) concluded that technological elements, organizational elements, and environmental elements significantly impact the HRIS adaptation in banking associations in Sri Lanka.

After the 1990s, manufacturing organizations also identified the momentousness of the people for the quality production process. They saw the workforce as a strategic asset and factor of value creation to 
the business. When carefully goes through the set of financial statements listed in the public companies, often sees in the Director's report mentioned that "our workforces are the great Asset, and they were the cause for our success." Decisions are the key output of the management process. Decision-making is the outcome of control and the reason for the positive or negative performances of the corporation. An organization's success depends on decisions. Without decisions, nothing happens in the corporate world. Effective and efficient choices always lead to achieving a competitive advantage. Managers are the persons who make decisions for the firms. However, technology helps managers to make accurate decisions at once (Armsrong, 2009). Decision making is a combination of selecting the accurate alternative among many. Based on quality information, the decision-makers choose the reliable and suitable one. In this context, information technology helps to generate quality information for decision making in the global scenario. Decisions should base on evidence, and evidence comes from the rich sources of information as externally and internally. HRIS is one of the best data-base that provides rich information to HR decisions. Moreover, the empirical studies confirmed that HRIS provided the best flat foam to work with big data. Big data always consist of variety, velocity, veracity, and volume (Taylor \& Francis, 2017).

Due to technology, the traditional ways of managing the workforce had been changed. Now employees are also moving to the new transformation process and motivate through the reduction of past workload. However, HRIS smooth the organizational operations with minimum errors. Hence this transformation process enables workers to acquire new proficiency, skills, and abilities. However, at the same time, effective HRIS helps workers to reduce work stress (Bullmash, 2015). The success of HRIS depends on several factors like internal processes, external conditions, and globalization. (Shrivastava \& Shaw, 2003). The HRIS alteration procedure is complex and critical because this transformation sometimes creates shock for the existing workers. Organizations must examine how to minimize the shock of existing employees, which provides awareness and training. Electronic, humanrelated practices encourage innovations within the organization.

In agreement with the empirical explanations, the main activities of HRIS include the input, process, and output of human capital data. Manually or technically, users can enter the data to the HRIS as input. The HRIS did the process and finally produces meaningful HR information for decision making. They are using the database HRIS store this output for future decisions in a confidential manner. In contrast, HRIS considers data security and storage tools. HRIS helps to store, maintain, and update data and generate output, which is the most attractive interface in the HRIS system.

HRIS was born with an intercept of human-related activities plus information technology. Human capital management demonstrated the policy procedures relate to managing people. IT explains the electronic functions relate to the computerized environment, including software, liveware, and hardware.

Provide meaningful information to the stakeholders is the dominant role of HRIS. HR professionals, managers, and employees used HRIS collaboratively. However, the reliability of the data is imperative to make a quality decision. Instead, the quality of HRIS directly affects the accuracy of the decision. The functional tasks of human capital management rely on HRIS. The practical functionality of HRIS drives an organization to achieve strategic goals. Moreover, HRIS is a main part of the management information system in the organization.

HRIS adaptation is a massive investment in small and medium enterprises. However, organizations should consider the benefits of investment before the execution of HRIS. On the employees' side, HRIS generates numerical benefits to them in alignment with documentation, payroll, leave management, etc. Moreover, organizational size directly influences the decision of HRIS adaptation (Taylor \& Francis, 2017). In line with the pros of globalization, firms are spread HRIS beyond the local boundaries. Using the internet, multinational firms jump from home country to other host or third countries. The internet created a drastic transformation to the traditional HR function. Because of technological advancement now HRIS has become a universal practice.

Successful HRIS execution is required to get the expected results. Otherwise, it becomes a loss of cost, time, and effort for the firm. Ineffective HRIS leads to inefficiency. Effective HRIS leads to achieving a competitive edge in the industry. According to (Armsrong, 2009), human capital management (HRM) is integrated planning to manage the workforce in organizations. According to (Bullmash, 
$\underline{2015)}$ defines a human resource information system (HRIS) as a desegregated structure which collects, store, and interprets HR-related data in an organization. According to most researchers' core ideas, HRIS is integral that tracks \& manages organization HR functions effectively and efficiently. The research Badhurudheen (2018) concluded that internal environmental factors such as the CEO's social technology skills, support of upper-level managers, centralization, and HRIS experience positively affected the HRIS. In respect to the empirical review conducted by (Aldmour, Love, \& Alzubi, 2013), environmental factors of internal and external have a significant effect on the success of HRIS.

Internal elements cite the willingness to implement HRIS, competency, organization's demographic characteristics, structure, managers' commitment, and support, culture, perceived benefits, sociodemographics of decision-makers, etc. External environmental factors consisted mainly of competitive pressure, software experts' license, branding, government rules, regulations, etc.

\subsection{Internal environmental factors}

Internal Environmental Factors demonstrate that the factors inside the organization, which affects the efficacy and the success of the HRIS. According to the research findings (Badhurudheen, 2018), the inside environment consisted of the below subsections.

\subsubsection{Willingness and Competency}

In line with the findings (Aldmour, Love, \& Alzubi, 2013), willingness refers to resource availability and the capacity to effectively implement the HRIS. Further, it mentioned that readiness has a substantial impact on implementing technology in an organizational context. Competency demonstrates the knowledge, skills, and abilities relevant to the HRIS implementation.

Technology readiness refers the effective IT adaptation and coordination in a Business firm (Iacovou, Benbasat, \& Dexter, 1995). Firms are more likely to implement IT-based technology using a specific IT department comprised of a high competency workforce (Iacovou, Benbasat, \& Dexter, 1995). Moreover, information technology knowledge requires today's business operations. Organizational readiness and competency are a leading internal environmental factor that includes sub-components of corporate, technical support, employee structure, education levels, etc.

\subsubsection{Organization's demographic characteristics}

An empirical work of (Aldmour, Love, \& Alzubi, 2013) explains that the organization's demographic characteristics include the firm's size, the period of experience with technology, nature of the firm, ownership, etc. Those demographic factors have a considerable impact on the adaptation of HRIS successfully.

\subsubsection{Managers commitment and support}

As per the study of (Aldmour, Love, \& Alzubi, 2013) explains that top-level and middle-level managers have an indispensable role in the adaptation process of HRIS. Employees need the manager's commitment and support for the adaptation. Top management can give the employees consent by providing verbal bits of advice; provide training and development programs, facilities and equipment, etc. The research of (Premkumar \& Roberts, 1999) mentioned that the manager's commitment and support facilitated the resources for the technological implementation process. (Shrivastava \& Shaw, 2003) Pointed out that managerial incompetency is one reason for large scale project failures and neither the technical errors (Thong, Yap, \& Raman, 1996), mentioned that top managers did the environmental analysis and feasibility analysis of the contemporary technological adaptations. Instead, management support can be visible or invisible. Upper-level support helps to establish the novelty. Effective upper management support leads to achieving virtue, leadership role.

\subsubsection{Corporate culture}

According to a documentary review conducted by (Aldmour, Love, \& Alzubi, 2013), corporate culture was the heart of organizational innovation. Culture attributes to the set of shared values and faith in a corporation. Cultures with flexible and open structures often lead to the success of the HRIS. The existential work of (Kitchell, 1995) mentioned that cultures with long-term direction had more tremendous HRIS adaptation success.

\subsubsection{Perceived benefits and novelty}

In consonance with the literature analysis conducted by (Aldmour, Love, \& Alzubi, 2013), perceived benefits and novelty included the competitive advantage, effectiveness, transparency, and innovations. 
IT innovations lead to achieving a sustainable competitive edge to the companies in a modern business context.

2.1.6. Social demographics of decision-makers

A literature criticism conducted by (Aldmour, Love, \& Alzubi, 2013) mentioned that the decision maker's attributes might affect the successful application of information technology in firms. Further pointed out HR managers have a crucial role in network development, coordination, communication, and induction on this process. Moreover, the effort of (Damanpour \& Schneider, 2006) found that gender does not affect the IT adaptation process. Well educated, competent managers are a great asset to generate new information, open to new ideas for the successful adaptation of HRIS.

\subsection{External environmental factors}

Those factors explain the outside elements that alter the success of the HRIS system. According to (Aldmour, Love, \& Alzubi, 2013) pointed out, external environmental factors significantly influence IT implementation. External environmental factors mainly include competitive pressure, support of software experts and branding, government rules and regulations, and Network externalities. According to the research findings (Badhurudheen, 2018), the external environment is a part of the below subsections.

\subsubsection{Competitive pressure}

Organizations often benchmark themselves with their competitors. This creates extra pressure on the managers. Literature shows that the competitor's rivalry and tension generate the best flat foam for IT implementation. According to (Aldmour, Love, \& Alzubi, 2013) mentioned that firms are now operating under the umbrella of a knowledge-based economy in which HR has become a strategic function. Within this strategic role, HR must reduce their unwanted costs and enhance the return of the business. The HRIS comes to the niche to manage human resources effectively. The effective HRIS streamlines the entire human resource activities in a systematic order. However, (Aldmour, Love, \& Alzubi, 2013) found that competition does not directly influence HRIS adaptation. However, the HRIS provides effective and quick decisions to the managers. Through this significant decision, they can gain a competitive advantage.

\subsubsection{Support of software experts and branding}

Sometimes the software services related to HRIS are provided by the third party outsiders or vendors. The continuous support of vendors is critical to develop and maintain an effective HRI system. The decision of technology adaptation significantly impacts the vendor support and marketing activities (Frambah, 1998). Branding and advertising are more critical factors to adopt new technology to the firm. Moreover, software experts have a major role in the corporate technology adaptation process (Aldmour, Love, \& Alzubi, 2013).

\subsubsection{Government rules and regulations}

The research scholar (Aldmour, Love, \& Alzubi, 2013) confirmed a significant relationship and the effect of government rules and regulations on IT implementation. Instead, government involvement, policies, and support provide positive motivation to the firms for IT adaptation. The government's grounds of the IT industry, like taxation, lead to provide better service to the clients for a reliable price. Moreover, the government has a responsibility to bridge the IT firms and organizations together. According to (Freeman, Rogers, \& Joel, 1999), younger employees are more curious about HRIS and IT adaptation. Further, the study illustrated that workers make a voice in their firms for technological changes. Internet speed, coverages are the leading factors to the success of HRIS. The government requires to build up national-level information and technology culture to achieve the above objectives.

\subsubsection{Network externalities}

According to (Aldmour, Love, \& Alzubi, 2013) value of elements significantly influence the size of the firm's network. Further, (Frambach \& Schillewaert, 2002) pointed out that the firm's number of users determined the system's value. Also, it derived that social influence significant to the intention of technology adaptation (Sykes, Venkatesh, \& Gosain, 2009). Moreover, empirical studies confirmed that external elements have a considerable impact on the success of technology adaptation. In the word of (Bileviciene, Bileviciute, \& Parazinskaite, 2015) mentioned, they found the purposeful cycle of development of cybernetics leads to useful information technology. According to Bangladesh's 
research, the firm's structure, technology, and operating context are significant to the success of HRIS adaptation (Taylor \& Francis, 2017) pointed out that firms are now shifting to effective HR services through the notion of e-HRM. When it comes to the (Noutsa, Wamba, \& Kamdjoug, 2016) confirmed that performance and the social elements influence HRIS implementation intention.

\section{Conceptual framework}

After the empirical studies, the researcher developed the following model which explores the two independent variables and one dependent variable.

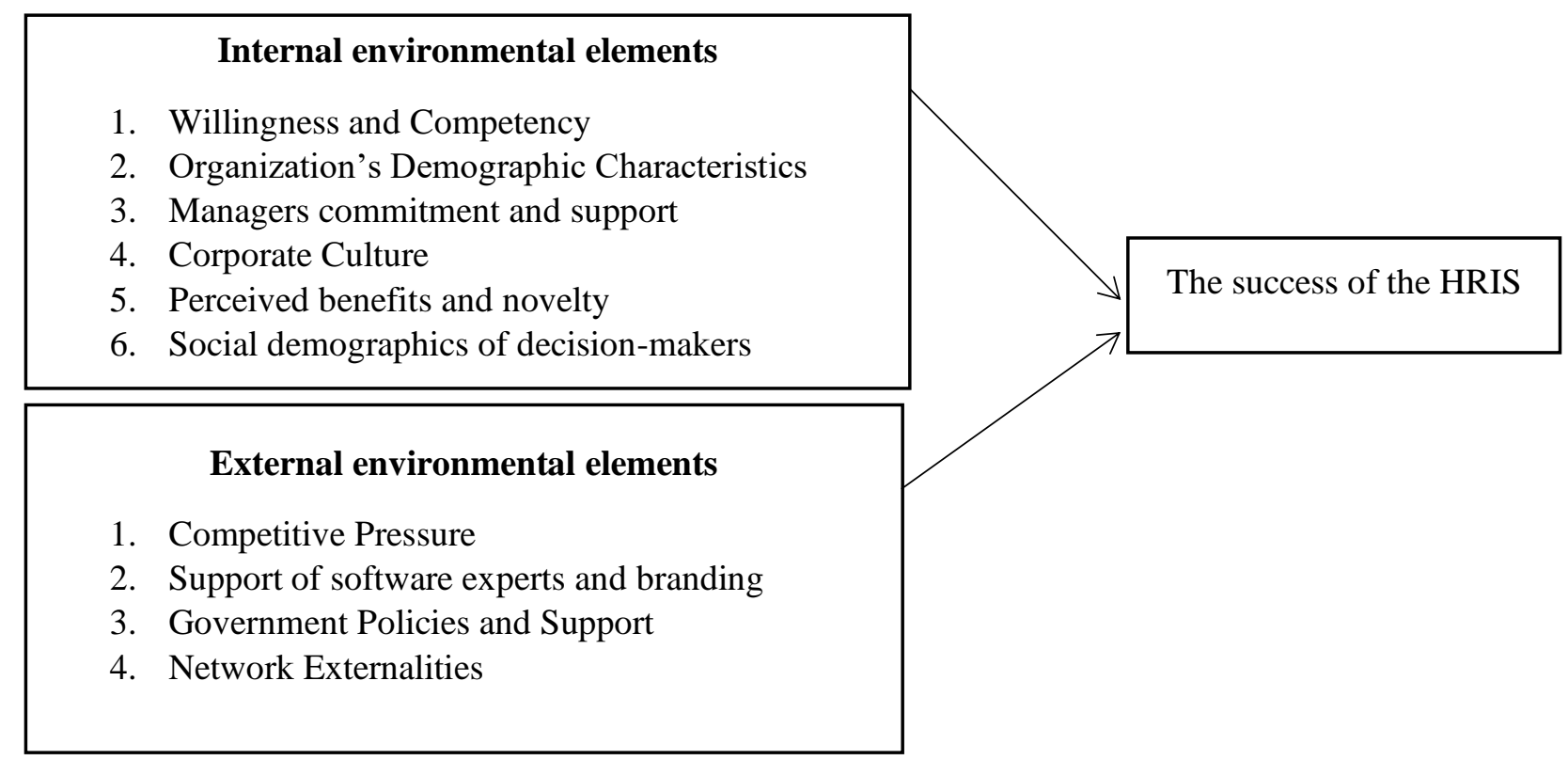

(Source: - Develop by the researcher)

The followings are the hypotheses of the study.

$\mathrm{H}_{0} 1$ - there is an impact of internal environmental elements and the Success of HRIS.

$\mathrm{H}_{0} 2$ - there is an impact of external environmental elements and the Success of HRIS.

\section{Research methodology}

The research design was deductive and quantitative. Find the elements influencing the success of HRIS in ABC manufacturing (Pvt) Ltd in a local context was the principal objective of this research. Staffs of ABC manufacturing (Pvt) Ltd were the total population. The researcher used the purposive sampling technique to select the respondents. A sample of 30 chosen executives in $\mathrm{ABC}$ manufacturing (Pvt) Ltd directly dealt with the HRIS System. The structured questionnaire was employed to collect primary data. The questionnaire included demographics and scales. Scales were formulated within the range of agreeing to disagree, including five points Likert plate. The respondents' rate was $100 \%$. Data analyzed using SPSS 20, including the tests of reliability and regression.

\section{Results and discussions}

\subsection{Validity and reliability}

Cronbach Alpha is in Table 1,

Table 1: Reliability

\begin{tabular}{|c|l|c|}
\hline & \multicolumn{1}{|c|}{ Instruments } & Cronbach "s Alpha \\
\hline 1 & Internal Environmental factors & 0.745 \\
\hline 2 & External Environmental factors & 0.732 \\
\hline 3 & Success of HRIS & 0.756 \\
\hline
\end{tabular}

The Cronbach's alpha value was above 0.7 for all the variables, which is statistically significant. 


\subsection{The impact between environmental elements and the success of HRIS}

In line with the linear regression, Internal and external environmental components are examined. The success of HRIS was the dependent variable, and inside and outside environmental components were the independent variables. The regression output confirmed that those independent variables were impacting the success of HRIS to 60.7 percent, as in Table 2. The coefficient of determination (R2 = $60.7 \%$ ) explains the variance of the success of HRIS to the inside and outside environmental elements. Instead, it confirmed the internal and external environmental elements have a significant impact on the success of HRIS.

Table 2: regression

Model Summary

\begin{tabular}{|l|r|r|r|r|}
\hline Model & \multicolumn{1}{|c|}{$\mathrm{R}$} & R Square & \multicolumn{1}{c|}{$\begin{array}{c}\text { Adjusted R } \\
\text { Square }\end{array}$} & $\begin{array}{r}\text { Std. Error of } \\
\text { the Estimate }\end{array}$ \\
\hline 1 & $.745^{2}$ & .698 & .607 & .41683 \\
\hline
\end{tabular}

Predictors: (Cons tant), intemal el ements, external elements,

Table 3: coefficients

\begin{tabular}{|c|c|c|c|c|c|c|}
\hline \multirow{2}{*}{\multicolumn{2}{|c|}{$\begin{array}{l}\text { Coefficientsa } \\
\text { Model }\end{array}$}} & \multicolumn{2}{|c|}{$\begin{array}{l}\text { Unstandardized } \\
\text { Coefficients }\end{array}$} & \multirow{2}{*}{$\begin{array}{l}\text { Standardized } \\
\text { Coefficients } \\
\text { Beta }\end{array}$} & \multirow[t]{2}{*}{$\mathrm{t}$} & \multirow[t]{2}{*}{ Sig. } \\
\hline & & B & Std. Error & & & \\
\hline \multirow{3}{*}{1} & (Constant) & -358 & .743 & & -728 & .420 \\
\hline & Intemal environmental elements. & .374 & .109 & .252 & 3.797 & .001 \\
\hline & $\begin{array}{l}\text { Extemal environmental } \\
\text { elements }\end{array}$ & .281 & .115 & .152 & 1306 & .062 \\
\hline
\end{tabular}

The table shows that internal environmental elements greatly impact the human resource information system's success than another factor. Instead, internal environmental factors $(\beta=25.2 \%$, to $=3.797$, $p$ $=0.001)$ statistically significant to the success of HRIS. External environmental factors $(\beta=15.2 \%$, to $=1.306, \mathrm{p}=0.062$ ) also have momentous impact on the success of HRIS. The beta values indicated the strength of the percentages. Higher percentages indicated the superior influence and the variance of independent predictors to the dependant predictor. The $t$ value explains the path validity between the variables, and it's significant. At the 0.01 level above, variables were statistically significant. Internal territory elements were the major influencing factor for the success of HRIS. According to (Badhurudheen, 2018) they were also proven that Internal environmental elements and External environmental elements had a considerable effect and relationship on the success of HRIS. As per the research finding of (Genc, 2014) also mentioned that HRM functions significantly desegregated with environmental factors. The research conducted by Bangladesh by (Khan, Hasan, \& Rubel, 2015) found that factors of an organization, Technology, and Environment of the entity impacted the HRIS adoption.

Conforming to (Wijethilaka, 2016), it concludes that technological factors, organizational factors, and environmental factors significantly impact the execution of HRIS in the banking sector. According to the review executed by Bangladesh researchers (Khan, Hasan, \& Rubel, 2015), stated that technology and environment were the most significant HRIS implementation factors in Bangladesh. Further, their study illustrated that HRIS has an assured effect on the performances of the firm. Also, the documentary review conducted by (Aldmour, Love, \& Alzubi, 2013) found that environmental elements directly affect the adaptation of HRIS. The researcher also derived that the success of HRIS significantly impacted internal environmental elements and external environmental elements. Finally, the researcher achieved the study's objective and confirmed that internal environmental elements and 
external environmental elements were significant to the success of HRIS in ABC manufacturing (Pvt) Ltd in the local ground.

\section{Conclusion}

HRIS database is the finest tool for tracking human-related data in business firms. Identify the elements influencing the success of HRIS in ABC manufacturing (Pvt) Ltd in Sri Lanka was the critical purpose of the present study. The study recognized several elements that influence the success of HRIS, which can broadly categorize as internal environmental elements and external environmental elements. Further, provide better direction to the personal managers to play a strategic role in the organizations effectively. Because of globalization, HRIS has suit an essential tool for managing people. The research affirmed that the success of HRIS significantly impacted internal environmental elements and external environmental elements. For the successful adaptation of technology, organizations must consider those inside and outside elements. Firms must ensure the success of HRIS through those factors. Moreover, an ineffective HRIS System creates various issues, problems, and disputes in an organized working environment.

Human beings are the most critical input to the production process. Human capital plays a significant role in determining the performance of a company. It is challenging to track information and convert that information to meaningful data because of people's uniqueness. HRIS adaptation is a considerable investment in micro and medium enterprises. However, before the implementation, organizations should consider the return on edge. The effective utilization of HRIS drives the organization to achieve strategic goals. However, HRIS is a significant part of the entity today. Finally, every element has their significant importance, but internal components are more critical for the success of HRIS, which indicate that internal factors were more significant in HRIS adaptation. The study's implication found that there was a substantial impact of interior elements and the external elements to the success of HRIS.

\section{Limitation and recommendation}

The sample was 30 and focused on one single company. Also, the researcher had chosen two determinants only. The researcher recommends increasing the respondent size and selects multiple organizations or industries. Then it will provide a better interpretation of the research problem in the future.

\section{Acknowledgement}

This inquest comes as a collaborative effort of various people. Without their support, this would never become a reality. The author acknowledged the top management and $\mathrm{ABC}$ manufacturing (Pvt) Ltd.

\section{REFERENCES}

Aldmour, R. H., Love, S., \& Alzubi, Z. (2013). Factors influencing the adoption of HRIS applications: a literature review. International Journal of Management \& Business Studies, 9-26.

Anitha, J., \& Aruna, M. (2015). Transformation towards Human Resource Information Systems. Journal of Management and Development Studies, 1-21.

Armsrong, M. (2009). Essential Human Resource Management Practices. United Kindom: Kogan page limited.

Badhurudheen, A. S. (2018). The impact of internal environmental factors on the level of adoption of Human Resource Information System: the case of manufacturing companies in Western Province of Sri Lanka. Journal of Information Systems \& Information Technology, 24-32.

Bileviciene, T., Bileviciute, E., \& Parazinskaite, G. (2015). Innovative trends in Human Resources Management. Economics \& Sociology, 1-16.

Bullmash, J. (2015). Human Resources Management And Technology. Canada: pearson.

Damanpour, \& Schneider. (2006). Phases of the adoption of innovation in organizations effects of environment, organization and top managers. British Journal of Management, 215-236.

Frambach, \& Schillewaert. (2002). Organizational innovation adoption a multi-level framework of determinants and opportunities for future research. Journal of Business Research, 163-176.

Frambah. (1998). An integrated model of organizational adoption and diffusion of innovations. European Journal of Marketing, 22-41.

Freeman, Rogers, R., \& Joel. (1999). What workers want. New York: Cornell University Press and Russell Sage Foundation. 
Genc, K. Y. (2014). Environmental factors affecting Human Resources Management activities of Turkish large firms. International Journal of Business and Management, 102-122.

Iacovou, Benbasat, \& Dexter. (1995). Electronic data interchange and small organizations Adoption and impact of technology. MIS Quarterly, 465-485.

Kagehi, S. j. (2015). Challenges of adopting Human Resource Information Systems in the information tecnology industry in kenya; A survey of selected IT firms. Africa: United states international university Africa.

Kaygusuz, I., Akgemci, T., \& Yilmaz, A. (2016). The impact of HRIS usage on organizational efficiency and employee performance: A research in industrial and banking sector in Ankara and Istanbul cities. International Journal of Business and Management, 14-52.

Khan, A. R., Hasan, N., \& Rubel, M. (2015). Factors affecting organizations adopting Human Resource Information Systems: a study in Bangladesh. Journal of Business and Management, 45-54.

Kitchell. (1995). Corporate culture, environmental adaptation, and innovation adoption qualitative/quantitative approach. Journal of the Academy of Marketing Science, 195-205.

Lantara, N. F. (2016). The use of Human Resources Information System for Organization and Motivation of south Sulawesi Gubernetorial office staffs. International Business Management, 385- 390.

Noutsa, F. A., Wamba, S. F., \& Kamdjoug, J. R. (2016). Exploring factors affecting the adoption of HRIS in SMEs in a Developing Country:Evidence from Cameroon. Journal of Catholic University of Central Africa, 1-14.

Premkumar, \& Roberts. (1999). Adoption of new information technologies in rural small businesses. Omega, 467-484.

Shrivastava, \& Shaw. (2003). Liberating HR through technology. Human Resource Management, 201222.

Sykes, Venkatesh, \& Gosain. (2009). Model of acceptance with peer support A social network perspective to understand employees" system use. MIS Quarterly, 342-371.

Taylor, \& Francis. (2017). Electronic Hrm four decades of research on adoption and consequences. The International Journal of Human Resource Management, 1-51.

Thong, Yap, \& Raman. (1996). Top management support, external expertise and information systems implementation in small businesses. Information Systems Research, 247-268.

Wijethilaka, R. (2016). Factors Affecting the Extent of Adoption of Human Resource Information System (HRIS) in Banking Sector in Sri Lanka. 3rd International HRM Conference (pp. 247 254). Sri Jayewardenepura: University of Sri Jayewardenepura. 